\title{
Cylindrical spirals myopathy
}

INSERM

\section{Source}

INSERM. (1999). Orphanet: an online rare disease and orphan drug data base. Cylindrical spirals myopathy. ORPHA:171886

Cylindrical spirals myopathy is a rare form of congenital myopathy characterized by global muscle weakness, hypotonia, myotonia and cramps in the presence of cylindrical, spiral-shaped inclusions (located in the central and/or subsacrolemmal areas of muscle fibers) in skeletal muscle biopsy. Abnormal gait, scoliosis, epileptic encephalopathy and psychomotor delay may be associated. 